\title{
EL SIMIL DE TEOCRITO XIII, 61-65
}

\author{
PATRICIA MABEL SACONI \\ Universidad de Buenos Aires
}

\begin{abstract}
Resumo: Entre os versos 61 e 65 do Idfio XIII de Teocrito, encontra-se um símile onde o poeta faz uma comparação entre Héracles e um leão. O que aparentemente se quer mostrar é a correspondência znitre o leáo audaz $e$ valente e o heroi. Mas, por outro lado, uma detalhada análise textual dos segmentos constitutivos do símile e sua relação com o contexto permitem observar que a construção do símile encobre uma aparente falta de lógica que somente pode ser clarificada da perspetiva da distáncia irónica.
\end{abstract}

Heracles es la figura protagonista del ciclo heroico dórico, conformado por numerosos episodios. Los rasgos distintivos del héroe: su filiación divina, la destreza, la fuerza y la valentía que le permiten realizar las hazañas heroicas, están presentes desde sus orígenes prehelénicos, donde se lo identifica con un daîmon ${ }^{1}$ de la fertilidad. Sus antecedentes se remontan hasta los testimonios del Cercano Oriente, que lo asimilan al dios Sandas de los hititas (cf. Levy, Rachel, 1934). Evoluciona literariamente a través de la épica, la lirica griega arcaica y la tragedia. En la época helenística, Teócrito lo ubica como figura protagonista en dos de sus composiciones. Una de ellas, el Idilio XIII.

Entre los versos 61 y 65 tiene lugar un simil donde se compara a Heracles con un león en el siguiente marco: durante la expedición de los Argonautas la tripulación de la nave Argo desembarca en las costas de Misia para descansar. El joven Hilas, compañero de Heracles, va en busca de agua para preparar la cena. Cuando se inclina sobre la fuente, tres Ninfas lo arrastan hacia el fondo impulsadas por la fuerza de Eros. Heracles lo busca desesperado, sin hallarlo (aqui se ubica el símil); luego de esperar al héro que no volverá a la nave, los argonautas abandonan el lugar:

(hós'hópot'eugéneios apóprothi lis esakoúsas) ${ }^{2}$

nebroû phthegxaménas tis en oúresin omophágos IIs

ex eunâs éspeusen hetoimotátan epi daita

Heraklées toiûtos en atriptoisin akánthais

paîda pothôn dedóneto, polýn d'epelámbane krôron.

"(Como un león de buena melena, escuchando a lo lejos)

cuando la cervatilla grito, un león carnivoro, en los montes, desde su guarida se apresuró contra la presa completamente dispuesta:

Heracles, tal, entre los espinos nunca rozados, deseando al niño se sacudia y abarcaba la espaciosa región. ${ }^{\text {”3 }}$

\footnotetext{
1. La transilteración se realizó tomando como punto de referencia la tabla propuesta por los profesores E. Prieto y R. Alcalde en su tradución de KIRK, 1962.

2. Este verso no aparece en $\mathrm{D}_{4} \mathrm{nl}$ en $\mathrm{K}$.

3. Tradución de la autora.
} 
Se define al simil como la figura que opera el desplazamiento de sentido in praesentia por adjunción: a los constituyentes de una estructura discursiva semánticamente cerrada se le agrega otra estructura también cerrada, articulándolas a partir de los rasgos comunes y señalando la clase límite en función de la cual es pertinente la suma de sentidos de ambas.

En la épica es de alta frecuencia la aparición de similes donde se realiza la comparación entre un héroe y un león, destacándose siempre la Bravura de la fiera:

- Iliada III, 21-29

"Entonces Menelao, el amado por Ares, 10 vió

llegar ante la tropa, marchando a grandes pasos,

y como un león se regocija cuando se encuentra con el cuerpo inmenso,

al descubrir un cornúpeto ciervo o una cabra silvestre,

$y$, hambriento, lo devora completamente, aunque

veloces perros y florecientes varones to persigan;

asi Menelao se regocijo al ver con sus ojos a

Alejandro, semejante a un dios -le pareció que castigaria al culpable

inmediatamente salto a tierra desde al carro con sus armas".

- lliada V, 161-164

"Como el león que se lanza entre la manada quiebra el cuello

de una novilla o una vaca que está pastando en la espesura, asi el hijo do Tideo, hizo bajar a ambos de los caballos,

forzándolos malamente. Luego les arrebato las armas."

- IIlada XII, 299-308

"Comenzó a marchar como el león nacido en los montes, que por mucho tiempo carece de carne, y su valeroso ánimo lo anima a atacar un rebaño e ir hacia la solida morada;

aunque encuentre en ella pastores

que vigilan alrededor de las ovejas con perros y dardos, trata de no huir del establo sin hacer el intento, sino que o lanzándose captura algo, o él mismo es primero expulsado con el dardo de una rápida mano.

Asi entonces el ánimo impulsaba a sarpedón, semejante a un dios, a asaltar el muro..."

- Odisea VI, 130-136

"Como el léon nacido en los montes, obedeciendo a su fuerza, empapado por la lluvia y azotado por el viento, con ojos

billantes, irrumpe entre los bueyes o las ovejas

o las ciervas silvestres: su estómago lo impulsa

a atacar el ganado e ir hacia la solida morada.

Asl, Odiseo estaba a punto de mezclarse entre las doncellas de hermosas trenzas aunque estaba desnudo: pues la necesidad lo alcanzaba."

- Iliada XXIV, 42-46

"De este modo el león conoce to salvaje,

el que cuando da lugar a su inmensa fuerza y su ánimo valeroso,

marcha contra los rebaños de los mortales para captura su

presa, asl, Aquiles perdio la compasión y no hubo

respeto..."

4. Las traduciones del texto homerico pertenecen a la autora. 
Excepto por los ejemplos de Odisea VI, 130-136 e lliada XXIV, 42-46 -en que el poeta critica en Aquiles el tratamiento del cadaver de Héctor- la agresividad, la valentía y la fiereza del animal sirven para realzar las virtudes propias del héro guerrero.

El símil teocriteo presenta como núcleo del término de comparación una fiera con los atributos propios del "animal heroico por excelencia", ávido de carne, ubicado en los montes y que certeramente se precipita contra la presa (cf. Friedrich, 1981)

De acuerdo con el criterio material de clasificación de los símiles la comparación puede darse en cuanto a los rasgos distintivos de los agentes -comparación por cualidad-, en cuando las actividades que se realizan -comparación por acción-, o a la combinación de ambos -comparación mixta.

El término comparado -Heracles- por la actitud en que se lo describe y la actividad que realiza, no se deriva de ninguno de los atributos esenciales del primer término.

Aunque mantiene sus atributos materiales: el arco, la maza y la piel de león, no es éste el Heracles de la tradición mftica anterior a Té́crito. A lo largo de la composición se insiste en su naturaleza humana, omitiéndose su naturaleza divina. En el Idilio XIII sus actos no están a la altura de los cánones heroicos. El héroe de los Doce Trabajos enloquece por la pérdida de un niño, abandona la nave y es injuriado por sus compañeros como desertor. Esto provoca una distorción de la lógica inherente a la figura del símil.

Del marco contextual del símil y su interrelación semántica con los dos términos asimilados resulta:

El león está lejos de la cervatilla

El león no emite sonido

El león escucha a la cervatilla

El león se dirige a la cervatilla

El león alcanzará su objetivo

La cervatilla emite el sonido

La cervatilla con el sonido

provoca su perdición

La cervatilla muere
Heracles está cerca de Hilas

Heracles grita

Heracles no escucha a Hilas

Heracles vaga sin rumbo

Heracies no alcanza su objetivo

Hilas responde al llamado de Heracles

Hilas grita para buscar

su salvación

Hilas no podrá volver a la superficie

Además, la descripción de la delicadeza de los cabellos rizados de Hilas, las actividades domésticas que realiza y principalmente, la completa pasividad que caracteriza su reación, asimilan al niño, en la estructura profunda, a una identidad opuesta a la identidad masculina de Heracles $y$, dentro del simil, Hilas está comparado con un nebrós que recibe predicación femenina.

Por lo tanto, desde el punto de vista de la secuencia narrativa, y dado que no está explicitada la clase límite (es decir: el rasgo común entre Heracles y el león) la asimilación es pertinente, no entre Heracles y el león, sino entre la cervatilla e Hilas.

De acuerdo con el relevamiento de las secuencias básicas coincidentes con un verso el el ldilio, que contienen alguna referencia a la figura del héroe, el símil aparece en el verso 64. Presenta- según el criterio gramatical para la clasificación de los similes- una articulación paratáctica, en la que el pronombre demonstrativo "toioûtos" explicita semánticamente al símil (cf. Garson, 1973). 
L. E. Rossi (Rossi, 1972) y R. Pretagostini (Pretagostini, 1980) han establecido que el ldilio XIII se divide en dos partes, la primera, designada "epistola narrativa" que abarca desde el verso 1 al 16 para Pretagostini y hasta el 15 para Rossi (quien considera al 16, verso de sutura); la segunda, el "epilio propiamente dicho", que abarca desde el verso 17 hasta el final.

Siempre dentro de la estructura de secuencias básicas, el 64 es el verso medial para la segunda parte -epilio-identificada en la división de la estructura compositiva.

La segunda parte comprende los versos 17 a 75 . En las secuencias básicas coincidentes con los versos, la figura de Heracles es aludida directa o indirectamente quince veces en la segunda parte. El simil se registra en la octava secuencia, y asi, para la estructura de secuencias se observa:

\section{7 secuencias: versos 19 a 58 \\ simil: verso 64 \\ 7 secuencias: versos 65 a 75}

Demonstrando un habilisimo manejo del lenguaje figurativo, el poeta establece en Heraklées - toioûtos el punto de inflexión donde las situacioes de Heracles e Hilas se tornan irreversibles. El simil, figura donde la coincidencia es la nota esencial, es utilizado por Teócrito para marcar la divergencia.

El pronombre demostrativo de cualidad en función comparativa es portador-en este contexto y en cuanto a las estructuras que relaciona- de una carga semántica opuesta a la que le es propia. El Heraklées - toioûtos - léon es un Heraklées ou - toioûtos - león. El desarrollo correcto del símil deberia ser Hýlas - toioûtos - nebrós.

La seleción de Heraklées / léon, invirtiendo la seleción lógica de los términos constitutivos del símil (entre los pares Heraklées / Hýlas y léon / nebrós) se corresponde con el establecimento de la figura mítica de Hilas, por mediación de su reflejo en el agua y posterior calda, en una dimensión diferente, a la que ha ingresado de manera irreversible.

El poeta construye el símil desde la perspectiva de esta nueva dimensión, onde la voz del que grita resulta "araiá", donde el que está cerca, está lejos, donde el que está vivo ya no está entre los vivos.

La obra de Teócrito constituye uno de los eslabones fundamentales para el estudio de la evolución del personaje mítico, cuyos origenes se remontan -según las evidencias arqueológicas- hasta el segundo milenio a.C.

La perspectiva de la distancia irónica caracteriza, dentro de su poieîn, la operación por medio de la cual Teócrito se apropia de la tradición mítica.

En el Idilio XIII, si bien el poeta permanece en el plano épico-mítico, a pesar de la atmósfera bucólica de la escena, a través del símil objetiviza literariamente el distanciamiento ironizante respecto del personaje de Heracles.

\section{ABSTRACT}

There is a simile in Theocritus'ldyII XIII, vv. 61-65. In this simile the poet set up a comparision betweem Herakles and a lion. It seems that this simile is to show the courage and braveness correlation. But, on the other side, a detail textual analysis of the constitutive elementes of it and their relation to the context, let us know that the figure construction hides an apparent illogical way of composition. The ironic distant perspective gives the right point of view about the meaning of this hellenistic passage. 


\section{REFERÉNCIAS BIBLIOGRÁFICAS}

FRIEDRICH, Rainer. On the compositional use of similes in the Odyssey. American Journal of Philology, Baltimore, vol. 102-2, 1981.

GARSON R. W. Formal aspects of theocritean comparisions. Classica Philology, Chicago, vol. LXVIII-1, 1973.

KIRK, G. S. Los poemas de Homero. Buenos Aires: Paidás, 1962.

LEVY, Rachel. The oriental origin of Herkles. Journal of Hellenistic Studies, Londres, LIV-1, 1934.

PRETAGOSTINI, Roberto. La strutura compositiva dei carmi teocritei. Quaderni Urbinati di Cultura Classica, Roma, vol. 34, 1980.

ROIG, Arturo. Similogia y Ecología en Homero. Fevista de Estudios Clásicos, Mendoza, vol. III, 1948.

ROSSI, L. Enrico. L'lla di Teocrito, epistola poetica ed epillio. Studi Cataudella, Univ. de Catania, vol. II, 1972.

SEGAL, Charles. Death by water: a narrative pattern in Theocritus. Hermes, Wiesbaden, vol. 102-1, 1974. 